\title{
Sensory impairment in hip-fracture patients 65 years or older and effects of hearing/vision interventions on fall frequency
}

\author{
Else V Grue' \\ Marit Kirkevold ${ }^{2}$ \\ Petter Mowinchel ${ }^{3}$ \\ Anette H Ranhoff ${ }^{4}$ \\ 'Diakonhjemmet University \\ College, Department of Research \\ and Development, Oslo, Norway; \\ ${ }^{2}$ University of Oslo, Department \\ of Medisin, Institute of Nursing \\ Sciences and Health Profession, Oslo, \\ Norway; ${ }^{3}$ Department of Paediatrics, \\ Woman-child division, Ullevål \\ University Hospital Oslo, Norway; \\ ${ }^{4}$ Diakonhjemmet Hospital, Geriatric \\ Unit, Oslo, Norway
}

\begin{abstract}
Aim: Examine the effect of nursing interventions to improve vision and hearing, systematic assessment, and referral to sensory specialists on falling.

Methods: Controlled intervention trial targeting hip fracture patients, 65 years and older, living at home and having problems seeing/reading regular print (VI) or hearing normal speech (HI). Intervention group $=200$, control group $=131$. The InterRAI-AcuteCare (RAI-AC) and the Combined-Serious-Sensory-Impairment interview guide (KAS-Screen) were used. Follow-up telephone calls were done every third month for one year.

Results: Mean age was 84.2 years, $79.8 \%$ were female, and $76.7 \%$ lived alone. HI was detected in $80.7 \%$ and VI in $59.8 \%$. Falling was more frequent among the intervention group $(\mathrm{P}=0.003)$ and they also more often moved to a nursing home $(\mathrm{P}<0.001)$ and were dependent walking up stairs $(\mathrm{P}=0.003)$.

Conclusions: This study could not document the effect of intervention on falling, possibly because of different base line characteristics (more females, $\mathrm{P}=0.018$, and more living alone $\mathrm{P}=0.011$ in the intervention group), differences in nursing care between subjects, and different risk factors. Interventions to improve sensory function remain important in rehabilitation, but have to be studied further.
\end{abstract}

Keywords: vision, hearing, hip fracture, falls, intervention, hospital

\section{Introduction}

Vision, hearing, and combined sensory impairment are common among older people ${ }^{1-3}$ and are known risk factors for falling. ${ }^{4,5}$ Falling is more common with increasing age and may result in injuries, such as fractures, that cause disability, fear of falling, and reduced mobility. Thus, falling is a threat to independent and healthy living. ${ }^{6}$

Some multifactorial fall-prevention studies have included analysis of interventions to improve vision ${ }^{7-9}$ and of recommendation for a hearing assessment. ${ }^{10}$ Vision and hearing impairment are risk factors for imbalance ${ }^{11-14}$ and may hinder mobility and extend the time required to regain health after illness. Although it seems obvious that improving hearing and vision would have a beneficial effect on reducing falls, the effect of such interventions in this context remains unclear. ${ }^{15}$ Patients with hip fractures have a high risk for new falls and should be particular targets for fall prevention. ${ }^{16-19}$

Among independently living hip fracture patients, vision impairment has been found to be more frequent than in persons without hip fracture $\mathrm{s}^{20,21}$ In addition, visually impaired hip fracture patients have fewer optometric and ophthalmic controls. ${ }^{22}$ Sensory impairment is an important risk factor for delirium ${ }^{23,24}$ which is frequent in this group and associated with falls ${ }^{25-27}$ and poor functional recovery. ${ }^{28-30}$ 
Unfortunately systematic evaluation of vision and hearing of elderly hospitalized patients is often neglected ${ }^{31,32}$ even though most sensory problems are potentially treatable or relieved by remedies and environmental adjustments. ${ }^{33-36}$ Information about sensory function is important for nursing care in elderly hip fracture patients because impairments may affect recovery. ${ }^{37}$ To our knowledge, there are no previous intervention studies in hip fracture patients with a major focus on improving vision and hearing function to reduce new falls.

The aim of this study was to examine, for one year after hip fracture, the effect of nursing interventions to improve vision and hearing on falling. Simple sensory tests and systematic assessment, referral to specialist services, and an educational program were included in the intervention.

\section{Methods}

\section{Sample and measurements}

The study was performed in two orthogeriatric wards and one orthopedic unit in Norway. All patients admitted for accidental fall and hip fracture from October 2004 to July 2006 in hospital A were considered for inclusion and recruited for either the intervention group or nonintervention controls (Figure 1). Patients in hospitals B and C were recruited as controls, according to the research nurse's schedule, from July 2005 to July 2006 (Figure 1).

The Resident Assessment Instrument-Acute Care (InterRAI-AC) ${ }^{38}$ and Combined Serious Sensory Impairment, interview guide (KAS-Screen) ${ }^{39}$ were used for screening and data collection.

The KAS-Screen consists of nine domains with 110 open and standardized questions. A sample of questions about vision and hearing was applied and is described in another paper.

The InterRAI-AC is validated and tested for reliability ${ }^{38}$ and consists of 11 domains with 62 clinical items, including socio-demographic data, physical and mental functioning, medical conditions, and services. It includes several subscales. ${ }^{38}$ The Norwegian version has been translated according to accepted procedures. The Cognitive Performance Scale ${ }^{40,41}$ identified cognitive impairment when the score was $>0$. The Delirium Score includes items concerning disorganized thinking and awareness and corresponds to the Confusion Assessment Method (CAM). ${ }^{42}$ Loss of Personal Activities of Daily Living (PADL) ${ }^{43}$ was defined as PADL $\geq 4$ (median value). Loss of Instrumental Activities of Daily Living, Involvement Scale, (IADL) ${ }^{44}$ was defined as IADL $\geq 4$ (median value). Severe pain ${ }^{45}$ was identified with a pain score of 3. Comorbidity was defined as having diagnoses from two or more ICD-10 classes (organ systems). Polypharmacy was defined as using six or more drugs. ${ }^{46} \mathrm{~A}$ fall was defined as an unexpected event in which the person comes to rest on the ground, floor, or lower level regardless of whether an injury was sustained. ${ }^{47} \mathrm{~A}$ fall injury was considered present when the incident resulted in a head injury or a fracture or wound.

\section{Data collection procedure}

Specially trained registered nurses interviewed and assessed the patients, explored the hospital records, and interviewed family and staff. The patients were assessed approximately 72 hours after surgery, and information refers to the 24-hour period preceding the assessment. Information about the patient's condition three days prior to the fracture and the number of falls during the previous three months was obtained.

The nurses also performed the follow-up telephone calls every third month for one year with the patient or with a proxy or primary nurse if the patient was unable to give information. Reports based on the InterRAI-AC were conducted at three and twelve months. Information about falls, activity level, living arrangements, and specialist assignments was requested at each call. The number of falls was recorded up to 12 months or to death or withdrawal from the study. The date of the first fall was set to 28 days before the telephone interview because the majority of the patients were unable to recall the exact date.

The hospital administration system was used to record readmissions to the hospital through the follow-up year. Reports from specialist services were also examined.

\section{Screening}

Sensory function was assessed with a hearing aid or glasses if normally used and available. Hearing impairment was categorized as mild (required quiet surroundings to hear well), moderate (a person talking must speak loudly, clearly, and precisely), or severe (extremely reduced hearing to no useable hearing) (score 1-3). Vision impairment was categorized as mild (reads large letters but not normal type sizes in newspapers), moderate (unable to read newspaper headlines, but recognizes objects), or severe (can only see light, colors, or contours to no vision) (score 1-3). Combined sensory loss was present with impairment in both vision and hearing. Patients who scored 0 (no impairment) on InterRAI-AC but reported vision and/or hearing to be fair to very poor (KAS-Screen) were classified as having impairment. 


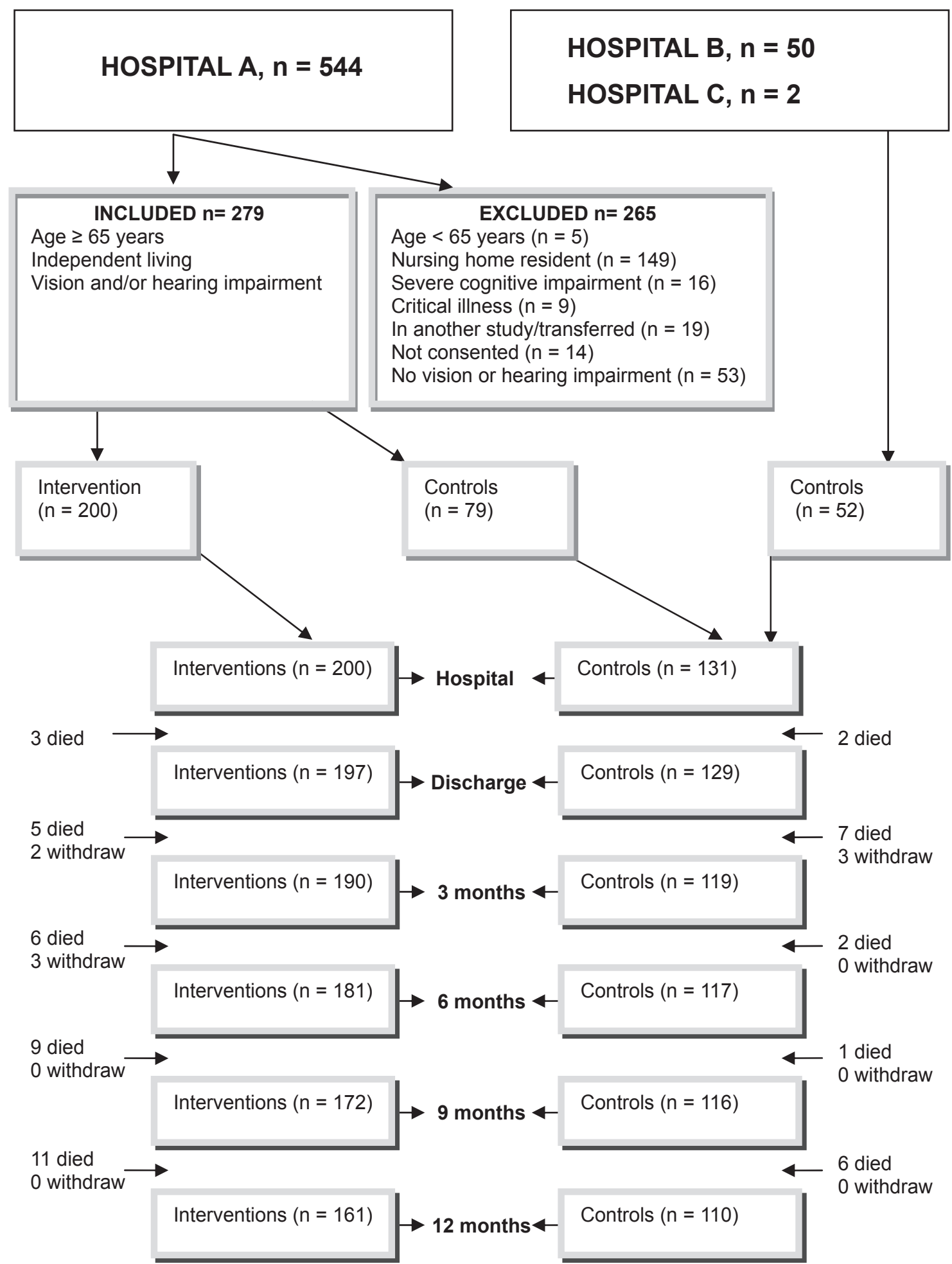

Figure I Flow chart showing the number of interventions and controls at time of inclusion and follow-up periods and the inclusion and exclusion criteria.

\section{Intervention}

The intervention was multifactorial and aimed at improving hearing and vision. Objective sensory tests were performed on those who scored positive and were candidates for intervention. A nurse (EVG) carried out vision examinations at the bedside. Donders' confrontation method, the Amsler grid test ${ }^{1}$ and Titmus Fly Stereotest ${ }^{48}$ gave information about, respectively, peripheral vision field, central field vision, and stereo depth perception. Visual acuity was measured by the Snellen method at a 3-m distance with glasses if normally 
used and available and was categorized according to the measurement on the better eye. An audiologist performed the hearing examination. Audiometric thresholds were established for frequencies of 500, 1000, 2000, and 4000 $\mathrm{Hz}$ and categorized by pure-tone average threshold on the better ear.

Ears were inspected with othoscopy and earwax removed. ${ }^{49,50}$ Hearing aid batteries, tubes, and filter were replaced when needed and service appointments organized. Glasses were cleaned daily during the hospital stay.

A pamphlet with information and individual education about vision and hearing, based on the work by Kee, Houde, and Tolson, ${ }^{51-53}$ was given to each patient. The educational method was dialogue, a conversation between equal partners aimed to obtain insight and understanding of sensory impairment and reveal coping strategies that the patient could apply to optimize vision and hearing. ${ }^{54}$ The educational session was timed to accommodate the patient's preference and treatment schedule. Patients were referred to a community occupational therapist when sensory remedies were needed.

Patients were offered an appointment with an ear-nose-throat (ENT) specialist or an audiologist when pure-tone audiometry (PTA) detected hearing thresholds of $\geq 35 \mathrm{~dB}$, if hearing was reported to be fair to poor (KAS-Screen), or if they had mild to severe hearing impairment (RAI-AC). ${ }^{55,56}$ The patients were also offered an appointment at an eye clinic (ophthalmologist and optometrist) when visual acuity (VA) $<0.8$, they failed the Donders test, Amsler grid, or Titmus Fly Stereotest, they reported vision to be fair to poor (KAS-Screen), or had mild to severe vision impairment (RAI-AC). ${ }^{22}$ Patients with regular visits to specialists were asked to bring a letter about the study at next consultation. To avoid long waiting lists for specialist assessments, arrangements were made with an eye clinic and a hearing clinic (ENT specialist and audiologists). Twenty-six patients were offered a home visit by an audiologist/audio pedagogue to help with hearing aids and communication skills. ${ }^{57}$

During the follow-up period, patients, relatives, and community staff received reminders about appointments with specialists and measures to improve sensory functions.

\section{Statistical analyses}

Based on the estimate from Shumway-Cook, ${ }^{18}$ we calculated that we should include 400 patients to obtain a power of $80 \%$ to detect a $15 \%$ reduction in falls (controls, $50 \%$ falls; interventions, $35 \%$ falls) with a significance level of $5 \%$. However, because of resource limitations, the final sample size was 331 . The power was reduced by $1 \%$.
Baseline and outcome data are presented as frequencies for categorical variables and mean values with standard deviation or median with interquartile range, when appropriate, for continuous variables. Differences between the intervention and control groups were tested using Pearson's Chi-square test for categorical variables; for continuous variables, the Mann-Whitney test or t-tests were used when appropriate. Odds ratios (ORs) are presented with 95\% confidence intervals (CIs) for outcome variables.

The association between intervention and survival rate (time to first fall) was assessed using a Cox proportional hazard model. Survival curves are presented graphically, controlled for age, gender, delirium, and urine incontinence. Dual sensory loss, new glasses/remedies, new/adjusted hearing aids, climbing stairs, feeling discouraged, nursing home residence, and living alone were excluded from the model one at a time in a step-down fashion. Likewise, any association between sensory treatment and survival rate (time to first fall) was assessed using the Cox proportional hazard model. The following variables were excluded from the Cox proportional hazards model: dual sensory loss, climbing stairs, feeling discouraged, nursing home residence, and living alone.

All analyses were by intention-to-treat, using a lastvalue-carried-forward strategy. The Statistical Package for Social Sciences ${ }^{58}$ was used for the statistical analyses and prepared as described in Peat and Barton. ${ }^{59}$ The level of significance was set to $0.05(5 \%)$.

\section{Ethics}

We had initially planned to do a controlled study by recruiting participants for intervention and control, respectively, every other month. The Regional Committee for Medical Research Ethics did not approve this design because support for improved sensory functions then would have been given to some patients but not to others in the same ward and possibly at same time. The study was approved when intervention participants were recruited first and control participants later. Written informed consent was obtained from all patients, and their relatives were informed.

\section{Results}

\section{Baseline characteristics}

The mean age was 84.2 years, $79.8 \%$ were female, and $76.7 \%$ lived alone. The intervention group and the control group differed in several variables, including gender and living alone (Table 1).

Vision impairment alone was detected in $19.3 \%$, hearing impairment alone in $40.2 \%$, and $40.5 \%$ had combined 
sensory impairment. Vision impairment $(\mathrm{P}=0.008)$ and dual sensory impairment $(\mathrm{P}=0.006)$ were detected more often among the controls (Table 1).

For visual function, $32.6 \%$ of the patients had mild, $13.0 \%$ moderate, and $7.8 \%$ severe impairment. The controls more often had mild or moderate impairment $(\mathrm{P}=0.001)$, as assessed using RAI-AC. Eighteen percent of the patients had two or more eye diagnoses. Fifty percent with cataract had not had surgery, and the proportion was higher in the intervention group $(\mathrm{P}=0.002)$ (Table 2$)$.

The severity of hearing impairment was similar between the two groups: $49.5 \%$ with mild, $27.8 \%$ with moderate, and only four patients $(1.2 \%)$ with severe loss, who were practically deaf, as assessed using RAI-AC. Eleven percent had problems related to acoustic trauma, diseases, congenital factors, or ototoxic medication (Table 2). Earwax was removed in $29.5 \%$ of the patients during the initial hospital stay.

Results from the pure-tone audiometry and visual acuity assessments $(n=186)$ is described in another paper.

\section{Specialist assignments}

On their own initiative some participants in the control group contacted specialists to take care of their vision and hearing impairment during the follow-up year (36.6\% and $10.7 \%$, respectively). As for the intervention group, $46.0 \%$ visited specialists for their vision and $36 \%$ for hearing impairments (Table 3). Both groups received little help in the first three months after discharge but specialist intervention frequencies increased as the year progressed. Of the 78 persons in the intervention group who did not see a vision specialist as recommended, 64\% were too ill, 24\% did not want to, were tired, or had no one to accompany them, $12 \%$ provided no explanation. Of the 99 intervention patients who did not visit a hearing specialist as recommended, 39\% were too ill, $47 \%$ replied that it was unnecessary or that they were too tired or had no one to accompany them, and $13 \%$ provided no explicit reason.

\section{Falls}

Cox proportional hazard model shows the association between intervention and survival rate (time to first fall) in curves controlled for age, gender, delirium, and urine incontinence $(p=0.004)$ (Figure 2). During the follow-up, falls were more frequent in the intervention group than in the control group (Table 3, Figure 2), but there was no difference in falls causing injuries between the groups (Table 3 ).

Table I Characteristics of participants at baseline given as number of cases (\%), unless otherwise stated, with $\mathrm{P}$ values for group differences

\begin{tabular}{|c|c|c|c|c|}
\hline Characteristics & All $n=331$ & Intervention $\mathbf{n}=\mathbf{2 0 0}$ & Control $n=|3|$ & $P$ value \\
\hline Age (years), mean (min, max) & $84.2(65,100)$ & $84.4(65,98)$ & $84.1(66,100)$ & 0.765 \\
\hline Gender (female) & $264(79.8)$ & $168(84.0)$ & $96(73.3)$ & 0.018 \\
\hline Living alone & $254(76.7)$ & $163(81.5)$ & $91(69.5)$ & 0.011 \\
\hline Vision impairment & $198(59.8)$ & $108(54.0)$ & $90(68.7)$ & 0.008 \\
\hline Hearing impairment & $267(80.7)$ & $161(80.5)$ & $106(80.9)$ & 0.925 \\
\hline Vision and hearing impairment & $134(40.5)$ & $69(34.5)$ & $65(49.6)$ & 0.006 \\
\hline Delirium, score 0-8 (score 8) & $50(15.1)$ & $20(10.0)$ & $30(22.9)$ & 0.02 \\
\hline Cognitive impairment, CPS ${ }^{a} 0-6$ (score $>0$ ) & $160(48.3)$ & $98(49.0)$ & $62(47.3)$ & 0.766 \\
\hline Discouraged, score mood/behavior 0-6 (score 6) & $64(19.3)$ & $52(26.0)$ & $12(9.2)$ & $<0.001$ \\
\hline PADL $^{\mathrm{b}}$ loss, PADLHierScale 0-6 (score $\geq 4$ ) & $184(55.6)$ & III (55.5) & $73(55.7)$ & 0.968 \\
\hline IADLc loss, Involvement Scale 0-2I (score $\geq 4$ ) & $169(51.1)$ & $104(52.0)$ & $65(49.6)$ & 0.672 \\
\hline Urine incontinence & $163(49.2)$ & $114(57.0)$ & $49(37.4)$ & $<0.001$ \\
\hline Severe pain, score $0-3$ (score 3 ) & $145(43.8)$ & $71(35.5)$ & $74(56.5)$ & $<0.001$ \\
\hline Underweight (BMI $<$ 20) & 79 (23.9) & $5 \mathrm{I}(25.5)$ & $28(21.4)$ & 0.389 \\
\hline Obese $(\mathrm{BMI} \geq 30$ ) & $15(4.5)$ & II (5.5) & $4(3.1)$ & 0.295 \\
\hline Unintended weight loss ( $5 \%$ last $30 \mathrm{~d}$ ) & $54(16.3)$ & $35(17.5)$ & $19(14.5)$ & 0.471 \\
\hline Polypharmacy (number of drugs $\geq 6$ ) & $180(54.4)$ & $105(52.5)$ & $75(57.3)$ & 0.396 \\
\hline Comorbidity (number of $I C D^{\mathrm{e}}-10 \geq 2$ ) & $268(8.0)$ & $160(80.0)$ & $108(82.4)$ & 0.580 \\
\hline LOSf days, median (min, max) & II $(2,110)$ & II $(4,7 I)$ & $10(2,110)$ & 0.301 \\
\hline
\end{tabular}

Notes: a Cognitive Performance Scale, ${ }^{b}$ Personal Activities of Daily Living, Instrumental Activities of Daily Living, ${ }^{\mathrm{d} B o d y}$ Mass Index, ${ }^{\mathrm{e}}$ International Classification of Diseases, 'Length of Stay. 


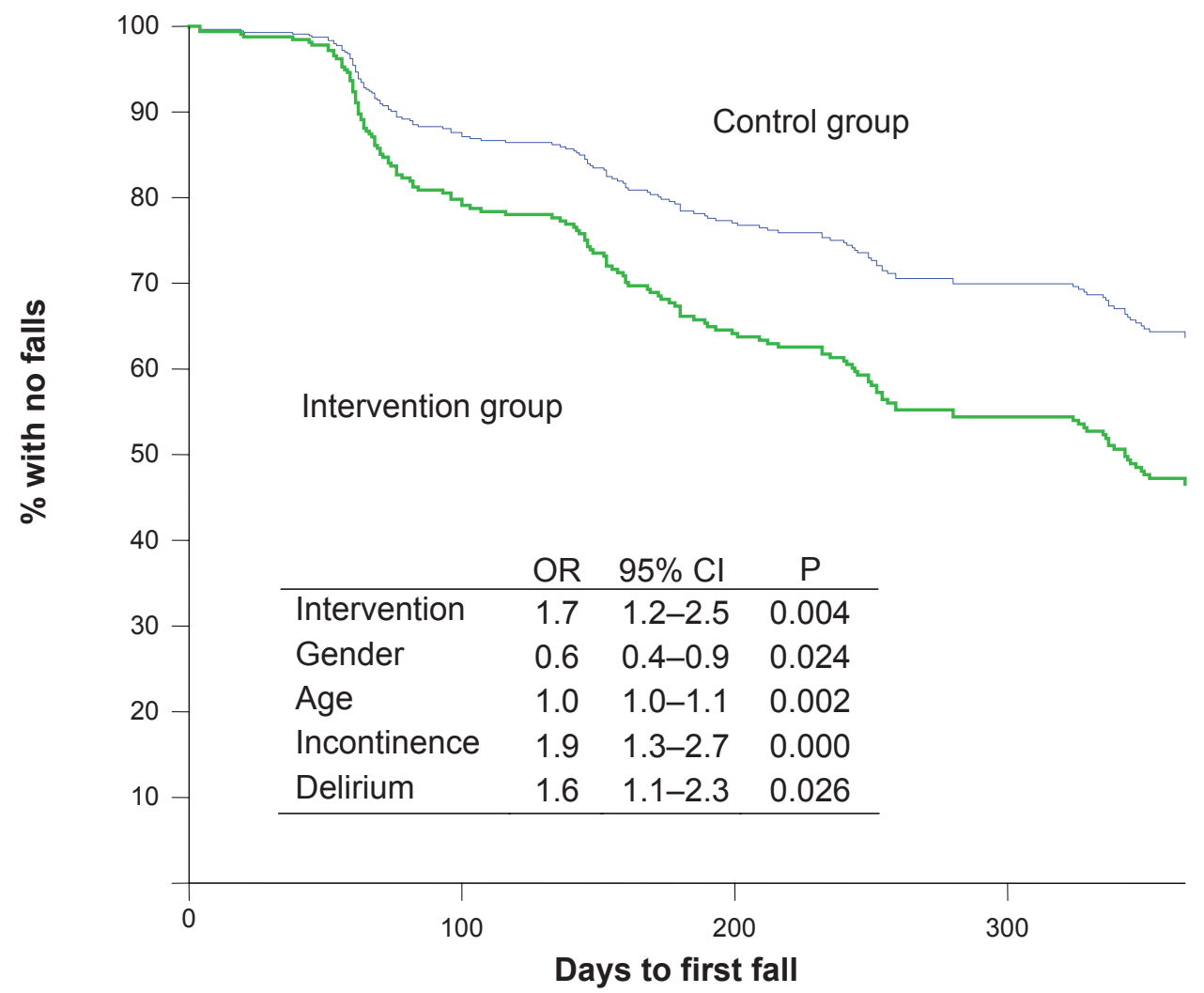

Figure 2 Kaplan-Meier curves presenting time to first fall for the intervention group $(\mathrm{n}=200$ participants) versus the control group ( $\mathrm{n}=|3| \mathrm{I}$ participants) controlled for by age, gender, delirium, and urine incontinence.

Abbreviations: OR, odds ratio; $95 \% \mathrm{CI}, 95 \%$ confidence interval for OR; P, P value.

Totally 117 (35.3\%) of all the subjects included in the study received treatment by hearing and/or vision specialists during the follow up year. Any association between the sensory treatment and survival rate (time to first fall) was likewise shown using the Cox proportional hazard model. There were no differences in falls between participants provided with sensory treatment/new sensory remedies and those without, independently of group assignment $(\mathrm{p}=0.395)$ (Figure 3 ). In analysis of subgroups of controls from hospitals B and C and the intervention group, there was no difference in falls.

Table 2 Self-reported characteristics of participants at baseline given as number of cases (\%), unless otherwise stated, with P values for group differences

\begin{tabular}{|c|c|c|c|c|}
\hline Characteristics & All $n=331$ & Intervention $\mathbf{n}=\mathbf{2 0 0}$ & Control $n=|3|$ & P value \\
\hline Cataract & $103(32.9)$ & $71(35.5)$ & $32(28.3)$ & 0.033 \\
\hline AMD & $4 \mid(I 2.4)$ & $24(12.0)$ & $17(13.0)$ & 0.792 \\
\hline Glaucoma & $64(19.3)$ & $42(21.0)$ & $22(16.8)$ & 0.343 \\
\hline Glasses used daily & $226(68.3)$ & I 46 (73.0) & $80(6 I .1)$ & 0.023 \\
\hline Vision remedies & I0I (30.5) & $73(36.5)$ & $28(21.4)$ & 0.003 \\
\hline$>2$ years since last vision check & I $37(4 \mid .4)$ & $85(42.5)$ & $52(39.7)$ & 0.612 \\
\hline Hearing loss, age related & $24 \mid(72.89$ & $177(88.5)$ & $64(48.9)$ & $<0.0001$ \\
\hline Hearing loss, disease related & $21(6.3)$ & $18(9.0)$ & $3(2.3)$ & 0.014 \\
\hline Hearing loss, noise/medication related & $14(4.2)$ & $4(2.0)$ & $10(7.6)$ & 0.013 \\
\hline Hearing aid used daily & $53 / 115(46.1)$ & $27 / 70(38.6)$ & $26 / 45(57.8)$ & 0.044 \\
\hline Hearing remedies, including warning & $64(19.3)$ & $44(22.0)$ & $20(15.3)$ & 0.129 \\
\hline$>2$ years since last hearing check & $245(78.5)$ & I 59 (79.5) & $86(76.8)$ & 0.575 \\
\hline
\end{tabular}


Table 3 Outcomes given as number of cases (\%), unless otherwise stated, with odds ratio (OR) and $95 \%$ confidence interval $(\mathrm{Cl})$ and $P$ values for group differences

\begin{tabular}{|c|c|c|c|c|c|c|}
\hline Outcomes & All $n=33$ I & Intervention $\mathbf{n}=\mathbf{2 0 0}$ & Controls $n=|3|$ & OR & $95 \% \mathrm{Cl}$ & $P$ value \\
\hline Dead & $52(15.7)$ & $34(17.0)$ & $18(13.7)$ & 1.3 & $0.7-2.4$ & 0.425 \\
\hline Nursing home & $67(20.2)$ & $53(26.5)$ & $14(10.7)$ & 3.0 & $1.6-5.7$ & $<0.001$ \\
\hline Living alone, $\mathrm{n}=264$ & $195(73.9)$ & I I4 (77.6) & $81(69.2)$ & 0.7 & $0.4-1.1$ & 0.126 \\
\hline Readmitted to hospital, $n=326$ & $139(42.0)$ & $83(42.1)$ & $56(43.4)$ & 0.9 & $0.6-1.5$ & 0.819 \\
\hline \multicolumn{7}{|l|}{ Falls } \\
\hline Patients who have fallen & I $46(44.1)$ & $102(51.0)$ & $44(33.6)$ & 2.0 & $1.3-3.2$ & 0.002 \\
\hline Patients who have fallen $\geq 2$ & $85(25.7)$ & $59(29.5)$ & $26(19.8)$ & 1.7 & $1.0-2.9$ & 0.049 \\
\hline Falls (mean/SD) & $433(1.3 / 2.5)$ & $310(1.6 / 2.6)$ & $123(0.9 / 2.2)$ & & $-1.1--0.1$ & 0.026 \\
\hline Median no. of falls/min-max & $0 / 0-17$ & $1 / 0-17$ & $0 / 0-15$ & & & \\
\hline Patients with fall injury & $60(4 I .1)$ & $42(4 \mid .2)$ & I8 (40.9) & 1.0 & $0.5-2.1$ & 0.976 \\
\hline Patients falling indoors, $n=146$ & $117(80.1)$ & $83(81.4)$ & $34(77.3)$ & 1.3 & $0.5-3.0$ & 0.569 \\
\hline \multicolumn{7}{|l|}{ Activity level } \\
\hline$<I$ hour activity last 3 days & $110(33.2)$ & $60(30.0)$ & $50(38.2)$ & 0.7 & $0.4-1.1$ & 0.123 \\
\hline Assistance when climbing stairs & $149(45)$ & $101(50.5)$ & $48(36.6)$ & 1.8 & I.I-2.8 & 0.013 \\
\hline Assistance, walking device, indoors & $217(65.6)$ & $136(68.0)$ & $81(61.8)$ & 1.3 & $0.8-2.1$ & 0.248 \\
\hline Assistance when going outdoors & $174(52.6)$ & $108(54.0)$ & $66(50.4)$ & 1.2 & $0.7-1.8$ & 0.519 \\
\hline Indoors last 3 days & $145(43.8)$ & $88(44.0)$ & $57(43.5)$ & 1.0 & $0.7-1.6$ & 0.930 \\
\hline Assistance getting up after falling & II3 (77.4) & $79(77.5)$ & $34(77.1)$ & 1.0 & $0.4-2.3$ & 0.981 \\
\hline \multicolumn{7}{|l|}{ Specialist assessment/treatment } \\
\hline Physiotherapy & $179(54.1)$ & II4 (57.0) & $65(49.6)$ & 1.3 & $0.9-2.1$ & 0.188 \\
\hline Hearing specialist assessment & $86(26.0)$ & $72(36.0)$ & $14(10.7)$ & 4.7 & $2.5-8.8$ & $<0.0001$ \\
\hline Hearing aid, new/upgraded & $46(14.6)$ & $39(20.2)$ & $7(5.8)$ & 4.1 & $1.8-9.6$ & $<0.0001$ \\
\hline Hearing remedies, new/upgraded & $30(9.1)$ & $29(14.5)$ & $\mathrm{I}(0.8)$ & & & \\
\hline Vision specialist assessment & $140(42.3)$ & $92(46.0)$ & $48(36.6)$ & 1.5 & $0.9-2.3$ & 0.092 \\
\hline Operation, new eye medication & $23(6.9)$ & $20(10.0)$ & $3(2.3)$ & & & \\
\hline Glasses, vision remedies & $55(16.6)$ & $44(22.0)$ & II (8.4) & 3.1 & $1.5-6.2$ & 0.001 \\
\hline
\end{tabular}

However, between the control group from hospital A and the intervention group (from the same hospital), there was a difference in falling $(\mathrm{P}<0.0001)$, in falling twice or more $(\mathrm{P}=0.003)$, and in the number of falls $(\mathrm{P}<0.0001$, SE difference $0.3,95 \% \mathrm{CI}, 1.7-0.5)$.

Most falls (65.1\%) happened during daytime in both groups. Patients in the intervention group fell more often because of "the legs giving away" ( $\mathrm{P}<0.0001)$. For other explanations of falls (stumbled, got stuck and slipped), there were no differences.

\section{Discussion}

Disappointingly, this intervention did not reduce the number of falls in the first year after a hip fracture. There was even an increase in falls in the intervention group compared to the controls in hospital A. However, the frequency of injuries from falls was the same between the intervention group and control group.
There are many possible explanations for these findings Other health and functional problems may have dominated and hidden the possible positive effect of the intervention. Muscle weakness, diabetic polyneuropathy, or cerebral- and cardiovascular diseases are common in this patient group and are well-known risk factors for falls. ${ }^{5,60,61}$

Although the nurse-patient dialogues were timed according to the patients' preference during the hospital stay, some patients were may not have been ready for this kind of conversation so early in the recovery process. The hip fracture, rehabilitation, pain, and discouragement might have dominated their focus of attention. The written information and quarterly telephone calls was intended to strengthen the patients' and relatives' understanding and reflection about actions to take to maximize vision and hearing function. However, these measures might not have been sufficient for patients to actually carry out necessary actions. 


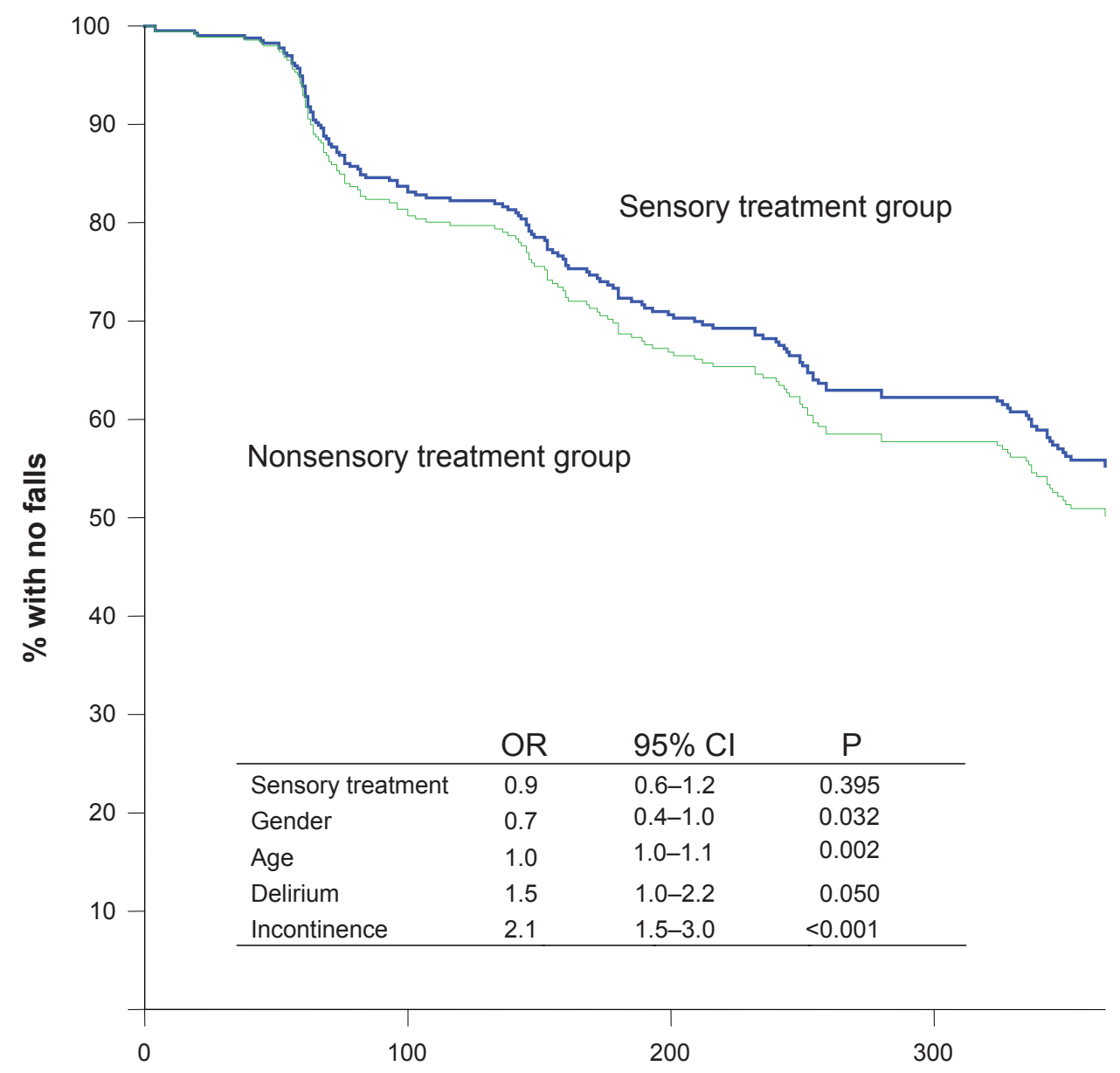

Days to first fall

Figure 3 Kaplan-Meier curves presenting time to first fall of persons who received sensory treatment versus persons who did not, controlled for by age, gender, delirium, and urine incontinence. Sensory treatment group, $\mathrm{n}=11 \mathrm{I}$; nonsensory treatment group, $\mathrm{n}=214$.

Abbreviations: $\mathrm{OR}$, odds ratio; $95 \% \mathrm{Cl}, 95 \%$ confidence interval for $\mathrm{OR} ; \mathrm{P}, \mathrm{P}$ value.

Furthermore, adjustment to new glasses, hearing aids, and other remedies might be difficult at a time of increased vulnerability. Additionally, medical treatment such as surgery and medication might have had adverse affects, including dizziness and reduced sensory function. This may have contributed to more falls, particularly shortly after treatment initiation. Another explanation could be that people who have begun a special intervention to improve vision and hearing are more active and have an increased risk for falling. However, lack of physical activity is probably a greater threat to this patient group. ${ }^{62}$

Differences between the intervention participants and the control group may explain the lack of effect of our intervention. Baseline data showed that more patients in the intervention group suffered from urine incontinence, were female, were living alone, and were discouraged (Table 1); all are risk factors for falling. ${ }^{5,63}$ In the follow-up period, more intervention participants resided in a nursing home and needed assistance when climbing stairs. The prevalence of falling is higher in nursing homes ${ }^{64,65}$ and among elderly with difficulties in climbing stairs. ${ }^{66}$ Being female and suffering from urinary incontinence were significant factors in a Cox regression model of falls in the current study. Delirium was a more common complication during the hospital stay among the control participants and is believed to increase the risk of falls. However, this effect might have interacted with the other factors.

Patients and their relatives recorded falls when the patients lived at home, while nursing staff recorded falls in nursing homes. Documentation of falls is a standard procedure in nursing homes in this city and might thus be more accurate than documentation of at home falls. Reporting of falls that 
involved injuries is probably more accurate than falls without injuries. There were no differences in falls causing injuries between the intervention and control groups.

The unexpected result may also have been biased by the fact that the patients were aware of whether they received interventions or not. ${ }^{67}$ The nurses who performed the interviews were not blinded to the groups and might also have influenced the results. Usually such factors will result in a bias towards a positive effect for the intervention group. ${ }^{68}$

The participants were not randomly selected for assignment to intervention or control. The intervention participants were included first, in a newly established orthogeriatric unit. During the study period, the routines and quality of care in the unit probably improved. The control participants were included later from this hospital (A) with more experienced staff and improved routines. Most likely the staff in hospital B had also gained high competence in the geriatric field. The orthogeriatric units were established at the same time. Comprehensive geriatric assessment (CGA), in combination with a prevention program, ${ }^{69}$ is a cornerstone in an orthogeriatric unit,,$^{70,71}$ and implementation is believed to take some time. Follow-up routines by a physiotherapist after three months were established in hospital A during the study period and might also have prevented falls in the control group.

It is not known whether the increased number of falls in the intervention group might have been even higher without the intervention, as indicated by Davison and colleagues. ${ }^{17}$ It is also possible that an intervention effect is delayed and might have manifested after a follow-up period. Consultations by specialists took place during the whole year and could support this explanation. It is also well known that it takes time to accept the idea that a hearing aid is necessary. ${ }^{72}$

The awareness of sensory impairment and need for intervention was communicated to the nursing staff during the intervention period. An improved attitude to vision and hearing improvement might therefore have been included in the daily nursing care of control patients. The number of control participants provided with visual treatment and remedies during the follow-up period supports this explanation. In addition, communication with the nurses in the follow-up interviews might have inspired control participants to see a specialist. In the analysis of patient subgroups according to "provided treatment/new sensory remedies" and "no treatment/no new sensory remedies," there was no difference in falls. The same result emerged between subgroups of controls from hospitals B and C and the intervention group. However, the control group in hospital A had less falls in the follow up year compared to the intervention group, most likely because of improved treatment and rehabilitation, better nursing care and the introduction of CGA and a fall prevention program. Fewer patients in the control group (Hospital A) felt discouraged and suffered from urine incontinence during the hospital stay, factors associated with increased risk of falling. ${ }^{5}$

The most likely explanations for the lack of effect of our intervention are different baseline characteristics, improvement of care from the time of inclusion of intervention participants to inclusion of controls, and differences in other health and functional problems that might have contributed to the risk of falling.

Another limitation of the study is that some patients with vision problems might not have been included because of shortcomings of the screening procedure; loss of peripheral visual fields, depth perception, and distance visual acuity were not tested in the screening procedure, and self report and a reading test would not be able to unmask such problems in every patient. We believe that the methods for detecting hearing impairment were better, although some patients reported "no hearing problem" yet were unable to hear normal speech. This discrepancy might be the result of a gradual adjustment to withdrawal from social contact.

A final limitation was that we did not receive specialist reports for the control patients and for patients with specialist contacts established prior to this study, but relied on the patient's own information about the consultations.

\section{Conclusions}

Vision, hearing, and combined impairments are very common in hip fracture patients, but this study could not document the effect of hearing and vision interventions conducted by nurses on improving falling frequency.

Nevertheless, in nursing care for hip fracture patients, we believe that detection of vision and hearing impairment and interventions to improve such functions are important not only to prevent future falls, but also for the rehabilitation process.

It is a challenge to design future studies to explore the effect of vision and hearing intervention on falling in this patient group. Other treatment and care must be similar, and for ethical reasons, patients with and without intervention must not be mixed. The best way to achieve appropriate data is probably to screen and randomize patients as soon as possible after surgery and then to transfer them to two different units that are as similar as possible in all variables except for the intervention. An alternative is to include and 
randomize all patients without screening because vision and hearing impairment is so common among hip fracture patients.

\section{Disclosure}

The authors report no conflicts of interest in this work.

\section{References}

1. Haegerstrom-Portnoy G, The Glenn A, Fry Award Lecture 2003. Vision in elders - summary of findings of the SKI study. Optom Vis Sci. 2005;82:87-93.

2. Borchgrevink HM, Tambs K, Hoffman HJ. The Nord-Trondelag Norway Audiometric Survey 1996-98: unscreened thresholds and prevalence of hearing impairment for adults $>20$ years. Noise Health. 2005;7:1-15.

3. Brennan M, Bally SJ. Psychosocial adaptations to dual sensory loss in middle and late adulthood. Trends Amplif. 2007;11:281-300.

4. Crews JE, Campbell VA. Vision impairment and hearing loss among community-dwelling older Americans: implications for health and functioning. Am J Public Health. 2004;94:823-9.

5. Tinetti ME, Inouye SK, Gill TM, et al. Shared risk factors for falls, incontinence, and functional dependence. Unifying the approach to geriatric syndromes. JAMA. 1995;273:1348-53.

6. Inouye SK, Studenski S, Tinetti ME, et al. Geriatric syndromes: clinical, research, and policy implications of a core geriatric concept. $J \mathrm{Am}$ Geriatr Soc. 2007;55:780-91.

7. Close J, Ellis M, Hooper R, et al. Prevention of falls in the elderly trial (PROFET): a randomised controlled trial. Lancet. 1999;353:93-7.

8. Day L, Fildes B, Gordon I, et al. Randomised factorial trial of falls prevention among older people living in their own homes. $B M J$. 2002;325:128.

9. Clemson L, Cumming RG, Kendig H, et al. The effectiveness of a community-based program for reducing the incidence of falls in the elderly: a randomized trial. J Am Geriatr Soc. 2004;52:1487-94.

10. Casteel C, Peek-Asa C, Lacsamana C, et al. Evaluation of a falls prevention program for independent elderly. Am J Health Behav. 2004;28(Suppl 1):S51-60.

11. Gerson LW, Jarjoura D, McCord G. Risk of imbalance in elderly people with impaired hearing or vision. Age Ageing. 1989;18:31-4.

12. Tinetti ME, Williams CS, Gill TM. Dizziness among older adults: a possible geriatric syndrome. Ann Intern Med. 2000;132:337-44.

13. Choy NL, Brauer S, Nitz J. Changes in postural stability in women aged 20 to 80 years. $J$ Gerontol A Biol Sci Med Sci. 2003;58:525-30.

14. Stevens KN, Lang IA, Guralnik JM, et al. Epidemiology of balance and dizziness in a national population: findings from the English Longitudinal Study of Ageing. Age Ageing. 2008;37:300-5.

15. Gillespie LD, Gillespie WJ, Robertson MC, et al. Interventions for preventing falls in elderly people. Cochrane Database Syst Rev. 2003;4: CD000340.

16. Tinetti ME. Clinical practice. Preventing falls in elderly persons. NEngl J Med. 2003;348:42-9.

17. Davison J, Bond J, Dawson P, et al. Patients with recurrent falls attending Accident and Emergency benefit from multifactorial intervention - a randomised controlled trial. Age Ageing. 2005;34:162-8.

18. Shumway-Cook A, Ciol MA, Gruber W, et al. Incidence of and risk factors for falls following hip fracture in community-dwelling older adults. Phys Ther. 2005;85:648-55.

19. Garcia R, Leme MD, Garcez-Leme LE. Evolution of Brazilian elderly with hip fracture secondary to a fall. Clinics. 2006;61:539-44.

20. Abdelhafiz AH, Austin CA. Visual factors should be assessed in older people presenting with falls or hip fracture. Age Ageing. 2003;32:26-30.

21. Squirrell DM, Kenny J, Mawer N, et al. Screening for visual impairment in elderly patients with hip fracture: validating a simple bedside test. Eye. 2005;19:55-9.
22. Cox A, Blaikie A, Macewen CJ, et al. Optometric and ophthalmic contact in elderly hip fracture patients with visual impairment. Ophthalmic Physiol Opt. 2005;25:357-62.

23. Edlund A, Lundstrom M, Karlsson S, et al. Delirium in older patients admitted to general internal medicine. J Geriatr Psychiatry Neurol. 2006; 19:83-90.

24. Inouye SK, Zhang Y, Jones RN, et al. Risk factors for delirium at discharge: development and validation of a predictive model. Arch Intern Med. 2007;167:1406-13.

25. Masud T, Morris RO. Epidemiology of falls. Age Ageing. 2001;30(Suppl 4):3-7.

26. Vassallo M, Sharma JC, Allen SC. Characteristics of single fallers and recurrent fallers among hospital in-patients. Gerontology. 2002;48:147-50.

27. Vassallo M, Sharma JC, Briggs RS, et al. Characteristics of early fallers on elderly patient rehabilitation wards. Age Ageing. 2003;32:338-42.

28. Dolan MM, Hawkes WG, Zimmerman SI, et al. Delirium on hospital admission in aged hip fracture patients: prediction of mortality and 2-year functional outcomes. J Gerontol A Biol Sci Med Sci. 2000;55: M527-34.

29. Marcantonio ER, Flacker JM, Michaels M, et al. Delirium is independently associated with poor functional recovery after hip fracture. J Am Geriatr Soc. 2000;48:618-24.

30. Olofsson B, Lundstrom M, Borssen B, et al. Delirium is associated with poor rehabilitation outcome in elderly patients treated for femoral neck fractures. Scand J Caring Sci. 2005;19:119-27.

31. Jack CI, Smith T, Neoh C, et al. Prevalence of low vision in elderly patients admitted to an acute geriatric unit in Liverpool: elderly people who fall are more likely to have low vision. Gerontology.1995;41:280-5.

32. Lim JK, Yap KB. Screening for hearing impairment in hospitalised elderly. Ann Acad Med Singapore. 2000;29:237-41.

33. Lichtenstein MJ. Hearing and visual impairments. Clin Geriatr Med. 1992;8:173-82.

34. Nottle HR, McCarty CA, Hassell JB, et al. Detection of vision impairment in people admitted to aged care assessment centres. Clin Experiment Ophthalmol. 2000;28:162-4.

35. Erber NP. Use of hearing aids by older people: influence of non-auditory factors (vision, manual dexterity). Int $J$ Audiol. 2003;42(Suppl 2):2S21-5.

36. Rosenberg EA, Sperazza LC. The visually impaired patient. Am Fam Physician. 2008;77:1431-6.

37. Lieberman D, Friger M. Visual and hearing impairment in elderly patients hospitalized for rehabilitation following hip fracture. $J$ Rehabil Res Dev. 2004;41:669-74.

38. Gray LC, Bernabei R, Berg K, et al. Standardizing assessment of elderly people in acute care: the interRAI Acute Care Instrument. $J$ Am Geriatr Soc. 2008;56:536-41.

39. Lyng K, Svingen EM. Identifying severe dual sensory loss in old age: evaluation of a screening method based on a checklist of issues. Oslo: Nova; 2001

40. Morris JN, Fries BE, Mehr DR, et al. MDS Cognitive Performance Scale. J Gerontol. 1994;49:M174-82.

41. Hartmaier SL, Sloane PD, Guess HA, et al. Validation of the Minimum Data Set Cognitive Performance Scale: agreement with the MiniMental State Examination. J Gerontol A Biol Sci Med Sci. 1995;50: M128-33.

42. Inouye SK, van Dyck CH, Alessi CA, et al. Clarifying confusion: the confusion assessment method. A new method for detection of delirium. Ann Intern Med. 1990;113:941-8.

43. Morris JN, Fries BE, Morris SA. Scaling ADLs within the MDS. J Gerontol A Biol Sci Med Sci. 1999;54:M546-53.

44. Landi F, Tua E, Onder G, et al. Minimum data set for home care: a valid instrument to assess frail older people living in the community. Med Care. 2000;38:1184-90.

45. Fries BE, Simon SE, Morris JN, et al. Pain in US nursing homes: validating a pain scale for the minimum data set. Gerontologist. 2001;41:173-9. 
46. Fialova D, Topinkova E, Gambassi G, et al. Potentially inappropriate medication use among elderly home care patients in Europe. JAMA. 2005;293:1348-58.

47. Lamb SE, Jorstad-Stein EC, Hauer K, et al. Development of a common outcome data set for fall injury prevention trials: the Prevention of Falls Network Europe consensus. J Am Geriatr Soc. 2005;53:1618-22.

48. Hasche H, Gockeln R, de Decker W. [The Titmus Fly Test-evaluation of subjective depth perception with a simple finger pointing trial. Clinical study of 73 patients and probands]. Klin Monatsbl Augenheilkd. 2001;218:38-43.

49. Lewis-Cullinan C, Janken JK. Effect of cerumen removal on the hearing ability of geriatric patients. J Adv Nurs. 1990;15:594-600.

50. McCarter DF, Courtney AU, Pollart SM. Cerumen impaction. Am Fam Physician. 2007;75:1523-8.

51. Kee CC, Miller V. Perioperative care of the older adult with auditory and visual changes. AORN J. 1999;70:1012-16, 1018-19; quiz 1020:1022-14

52. Tolson D, Nolan M. Gerontological nursing. 4: Age-related hearing explored. Br J Nurs, Feb 24-2000. 9:205-8.

53. Houde SC, Huff MH. Age-related vision loss in older adults. A challenge for gerontological nurses. J Gerontol Nurs. 2003;29:25-33.

54. Hage AM, Lorensen M. A philosophical analysis of the concept empowerment; the fundament of an education-programme to the frail elderly. Nurs Philos. 2005;6:235-46.

55. Popelka MM, Cruickshanks KJ, Wiley TL, et al. Low prevalence of hearing aid use among older adults with hearing loss: the Epidemiology of Hearing Loss Study. J Am Geriatr Soc. 1998;46:1075-8.

56. Smeeth L, Fletcher AE, Ng ES, et al. Reduced hearing, ownership, and use of hearing aids in elderly people in the UK - the MRC Trial of the Assessment and Management of Older People in the Community: a cross-sectional survey. Lancet. 2002;359:1466-70.

57. Heine C, Browning CJ. Communication and psychosocial consequences of sensory loss in older adults: overview and rehabilitation directions. Disabil Rehabil. 2002;24:763-3.

58. SPSS. Base 10.0 User's guide. Chicago: Marketing Department SPSS Inc; 1999.
59. Peat J, Barton B. Medical statistics: a guide to data analysis and critical appraisal. Malden: Blackwell; 2005.

60. Ganz DA, Bao Y. Shekelle PG, et al. Will my patient fall? JAMA. 2007;297:77-86.

61. Stevens JA, Olson S. Reducing falls and resulting hip fractures among older women. MMWR Recomm Rep. 2000;49(RR-2):3-12.

62. Stenvall M, Elinge E, von Heideken Wagert P, et al. Having had a hip fracture - association with dependency among the oldest old. Age Ageing. 2005;34:294-7.

63. Kharicha K, Iliffe S, Harari D, et al. Health risk appraisal in older people 1: are older people living alone an "at-risk" group? Br J Gen Pract. 2007;57:271-6.

64. Rubenstein LZ, Josephson KR, Robbins AS. Falls in the nursing home. Ann Intern Med. 1994;121:442-51.

65. Fonad E, Wahlin TB, Winblad B, et al. Falls and fall risk among nursing home residents. J Clin Nurs. 2008;17:126-34.

66. Bergland A, Jarnlo GB, Wyller TB. Self-reported walking, balance testing and risk of fall among the elderly. Tidsskr Nor Laegeforen 2006;126:176-8.

67. Mackenzie L, Byles J, D'Este C. Validation of self-reported fall events in intervention studies. Clin Rehabil. 2006;20:331-9.

68. Altman D. Practical statistics for medical research. 1st ed. London: Chapman and Hall; 1991.

69. Stenvall M, Olofsson B, Lundstrom M, et al. A multidisciplinary, multifactorial intervention program reduces postoperative falls and injuries after femoral neck fracture. Osteoporos Int. 2007;18:167-75.

70. Antonelli Incalzi R, Gemma A, Capparella O. Orthogeriatric Unit: a thinking process and a working model. Aging Clin Exp Res. 2008;20:109-12.

71. Pioli G, Giusti A, Barone A. Orthogeriatric care for the elderly with hip fractures: where are we? Aging Clin Exp Res. 2008;20:113-22.

72. Gussekloo J, de Bont LE, von Faber M, et al. Auditory rehabilitation of older people from the general population - the Leiden 85-plus study. Br J Gen Pract. 2003;53:536-40. 
